\title{
Antigen Receptor Variable Region Repertoires Expressed by T Cells Infiltrating Thyroid, Retroorbital, and Pretibial Tissue in Graves' Disease*
}

\author{
ARMIN E. HEUFELDER, BJÖRN E. WENZEL, AND PETER C. SCRIBA \\ Molecular Thyroid Research Unit, Department of Internal Medicine, Ludwig Maximilians University, \\ 80336 Munich, Germany
}

\begin{abstract}
To date, it has remained unclear whether $\mathrm{T}$ cells infiltrating thyroid, retroorbital, and pretibial tissue of patients with Graves' ophthalmopathy and pretibial dermopathy represent a primary immune response that is directed against certain antigenic determinants shared among these involved tissues. To characterize these $\mathrm{T}$ cells at the molecular level, we compared the $T$ cell antigen receptor $(\mathrm{TcR})$ variable $(V)$ region gene usage in thyroid, retroorbital, pretibial tissue, and peripheral blood mononuclear cells of two patients with Graves' disease, ophthalmopathy, and pretibial dermopathy. Ribonucleic acid was extracted, reverse transcribed, and amplified using the PCR and $22 \mathrm{~V} \alpha$ and $23 \mathrm{~V} \beta$ gene-specific oligonucleotide primers. The resulting TcR V $\alpha$ and $V \beta$ transcripts were verified by Southern hybridization analysis using $\mathrm{TcR} C$ region-specific, digoxigenin-la-
\end{abstract}

beled oligonucleotide probes. In addition, complementarity determining regions 3 and junctional regions of $T c R V \beta$ genes were sequenced. Marked similarities of intrathyroidal, retroorbital, and pretibial TcR $V \alpha$ and $V \beta$ gene repertoires were noted with respect to the degree of $\mathrm{TcR} V$ gene restriction and the patterns of individual $\mathrm{V}$ genes expressed. Sequence analysis of junctional domains of $V \beta$ families revealed oligoclonality of intrathyroidal, retroorbital, and pretibial $\mathrm{T}$ cells. In addition, certain conserved junctional motifs were shared by $\mathrm{T}$ cells derived the thyroid gland and the extrathyroidal sites. Our results suggest that in the two patients with Graves' disease and extrathyroidal manifestations studied, similar antigenic determinants may have contributed to the recruitment and oligoclonal expansion of $T$ cells both within the thyroid gland and at the involved extrathyroidal sites. (J Clin Endocrinol Metab 81: 3733-3739, 1996)
$\mathrm{T}^{\mathrm{H}}$ EE ETIOLOGY of Graves' ophthalmopathy (GO) and pretibial dermopathy (PTD) and the reasons for the preferential involvement of the retroorbital and pretibial space are poorly understood (1-5). During the active stages of $\mathrm{GO}$, infiltration of the retroorbital tissue by mononuclear cells is frequently observed $(1,2)$. The cellular infiltrate within the retroorbital tissues in $\mathrm{GO}$ consists mainly of $\mathrm{T}$ lymphocytes, macrophages, and, to a lesser extent, B cells and natural killer cells $(6-8)$. The $\mathrm{T}$ cell component includes both $\mathrm{CD}^{+}$and $\mathrm{CD} 8^{+} \mathrm{T}$ lymphocytes, many of which express CD45RO, suggesting that they are major histocompatibility complex (MHC) class I and II restricted memory $\mathrm{T}$ cells $(8-10)$. PTD occurs in a small proportion of patients with Graves' disease (GD), most of whom have ophthalmopathy and high serum titers of TSH receptor-directed antibodies (3-5). Both processes are likely to be driven by $\mathrm{T}$ cells that access and infiltrate the retroorbital and pretibial space via certain adhesion molecules and release various cytokines capable of stimulating cell proliferation, GAG synthesis, and the expression of immunomodulatory molecules in microvascular endothelial cells and fibroblasts (1, 2, 10-13). In support of this concept, retroorbital and pretibial fibroblasts

Received March 15, 1996. Revision received May 16, 1996. Accepted May 21, 1996

Address all correspondence and requests for reprints to: Armin E. Heufelder, M.D., Molecular Thyroid Research Unit, Medizinische Klinik, Klinikum Innenstadt, Ludwig-Maximilians-Universität, Ziemssenstraße 1, 80336 Munich, Germany.

* This work was supported in part by grants (to A.E.H.) from Deutsche Forschungsgemeinschaft, Bonn, Germany (He 1485/5-1, Gerhard Hess program), and the Friedrich-Baur-Foundation, Munich, Germany. have recently been shown to act as targets of the autoimmune process in GO and PTD (14). However, although these mechanisms may be sufficient to explain certain aspects of how GO and PTD may evolve and be propagated, the primary antigen for these presumed autoimmune manifestations has remained elusive. The close clinical association between the hyperthyroidism of GD, GO, and PTD suggests that the antigen responsible for these diverse conditions may be shared by the thyroid gland and extrathyroidal tissues (11).

$\mathrm{T}$ cells specifically recognize processed antigens in conjunction with MHC molecules through their $\mathrm{T}$ cell receptors (TCR) which consist mostly of $\alpha$ - and $\beta$-chain heterodimers. The TcR $\alpha$-chain consists of variable (V), joining (J), and constant $(C)$ regions, whereas the $\beta$-chain consists of $V$, diversity (D), joining, and constant regions. They are designated $\mathrm{V} \alpha, \mathrm{J} \alpha$, and $\mathrm{C} \alpha$ or $\mathrm{V} \beta, \mathrm{D} \beta, \mathrm{J} \beta$, and $\mathrm{C} \beta$, respectively. The antigen specificity of the TCR is defined by the $V$ domains encoded by $V, D$, and $J$ gene elements that are rearranged and joined during $\mathrm{T}$ cell differentiation. The clonotypic rearrangement of germ-line $\mathrm{V}, \mathrm{D}, \mathrm{J}$, and $\mathrm{C}$ genes provides for TcR recognition of a vast array of $\mathrm{MHC}$-antigen complexes. The specific interaction of TcRs with MHC-peptide complexes is mediated by three Ig-like complementary-determining regions (CDR1, CDR2, and CDR3) (15). Germ-line V genes encode both the CDR1 and CDR2 domains, which presumably contact polymorphic MHC determinants. The CDR3 domain is encoded by both germ-line $\mathrm{V}$ and $\mathrm{J}$ genes and nontemplated nucleotide modifications ( $\mathrm{N}$ regions) located at the V-J or V-D-J interface of rearranged TCR $\alpha$ and $\beta$ genes, respectively. The recognition of $\mathrm{MHC}$-peptide complexes by $\mathrm{T}$ cells is frequently characterized by the selective or re- 
stricted use of particular TcR germ-line (V and J genes) and CDR3 sequence combinations. Such biases may reflect the need for a conserved structural framework and peptide contact sites in TcR recognition events (16).

Simultaneous screening of samples for $\mathrm{TcR}$ gene rearrangements or their transcription of messenger ribonucleic acid (RNA) has been facilitated greatly by the availability of PCR-based TcR V region gene phenotyping. Using this technique, in both humans and animal models, restricted heterogeneity of the $\mathrm{T}$ cell response was detected in several autoimmune diseases (17-20), including thyroid autoimmune diseases and GO (21-24). In addition, we recently demonstrated restricted usage of $T C R \mathrm{~V}$ region gene families in $\mathrm{T}$ lymphocytes derived from pretibial biopsies of patients with active PTD (25). Although these studies suggested that specific antigens are targeted by $\mathrm{T}$ lymphocytes present at these distinct sites, analysis of intrathyroidal, retroorbital, and pretibial TcR V gene repertoires in individual patients has been prohibited by the lack of appropriate study material. Comparative analysis of local TcR V gene usage at the involved sites of individual patients with GD may help to determine whether the hypothesis of a shared antigen between the thyroid gland and the extrathyroidal manifestations is supported at the molecular T cell level.

In this study, using PCR-based phenotyping of $T c R ~ V$ region genes and sequencing of junctional regions of dominant $V \beta$ genes, we analyzed the expression of the known $V \alpha$ and $V \beta$ gene families in $T$ cells infiltrating the thyroid gland and various extrathyroidal sites of two patients with GD, severe ophthalmopathy, and PTD. Our results indicate oligoclonality of TcRs and striking similarities of TcR V gene repertoires at the intra- and extrathyroidal manifestations in these two patients with GD.

\section{Materials and Methods}

\section{Study subjects}

Patient 1, a 54-yr-old white female, presented to her local physician in June 1993 with palpitations, sweating, irritability and a 9-lb weight loss. She had previously been healthy except for chronic bronchitis due to heavy smoking ( 25 cigarettes/day). Graves' hyperthyroidism was diagnosed based on typical clinical signs and symptoms, the presence of mild bilateral ophthalmopathy, and heterogeneous, markedly elevated technetium uptake of $9.6 \%$ on thyroid scintigraphy. Thyroid function tests were as follows: basal TSH, less than $0.03 \mathrm{mEq} / \mathrm{L}$; free $\mathrm{T}_{4}, 580$ $\mathrm{pg} / \mathrm{L}$; free $\mathrm{T}_{3}, 14.7 \mathrm{fg} / \mathrm{L}$; thyroglobulin antibodies, $480 \mathrm{mU} / \mathrm{L}$; thyroid peroxidase antibodies, $1600 \mathrm{mU} / \mathrm{L}$; and TSH receptor stimulating index, 17.8 , as determined by stimulation of cAMP production in rat thyroid cells. Thyroid ultrasound revealed a large multinodular goiter $(78 \mathrm{~mL})$ with marked hypoechogenicity. Antithyroid medication with carbimazole $(20 \mathrm{mg}$, orally, twice daily) was started; however, the patient was still hyperthyroid after 3 weeks of therapy. A euthyroid state was achieved only after the carbimazole dose had been increased to 60 $\mathrm{mg} /$ day. Near-total thyroidectomy was performed without complications, and a small piece of thyroid tissue was immediately frozen in liquid nitrogen. Four months later, while the patient was euthyroid with replacement therapy of $125 \mu \mathrm{g} /$ day levothyroxine, progression of ophthalmopathy was noted by her ophthalmologist; however, treatment with glucocorticosteroids or orbital irradiation was not initiated. Smoking was strongly discouraged, with minimal success. Two months later, the patient presented with an infiltrative dermopathy that extended over both anterior pretibial areas. Lesional biopsies, taken from both legs for immunohistochemical studies, were consistent with pretibial dermopathy. One deep biopsy specimen was quickly frozen in liquid nitrogen and reserved for further study. In January 1994, the patient was referred for progressive severe ophthalmopathy. Marked bilateral proptosis, periorbital edema, diplopia, left optic neuropathy, and incipient exposure keratitis of the left eye due to incomplete lid closure were noted. Urgent surgical decompression of the left orbit was performed, resulting in rapid recovery of optic nerve function and restoration of lid closure. During the surgical procedure, a small biopsy of retroorbital connective tissue was frozen in liquid nitrogen, and a blood sample was taken for preparation of peripheral blood mononuclear cells. Postoperatively, the patient underwent orbital irradiation and oral glucocorticoid therapy, with acceptable long term success. Human leukocyte antigen (HLA) haplotyping of patient 1 revealed HLA class I (A2, B7, Bw57, Cw6), HLA class II (DR2 DR7).

Patient 2, a 44-yr-old white female, presented for evaluation of progressive periorbital swelling and visual impairment. She had been diagnosed with Graves' hyperthyroidism 3 yr ago and undergone successful treatment with radioiodine, followed by supplementation with $75 \mu \mathrm{g} /$ day levothyroxine. Thyroid function tests confirmed a euthyroid state (TSH, $1.2 \mathrm{mU} / \mathrm{L}$; free $\mathrm{T}_{4}, 140 \mathrm{pg} / \mathrm{L}$; lree $\mathrm{T}_{3}, 2.9 \mathrm{gg} / \mathrm{L}$ ) and a markedly elevated TSH receptor stimulating index of 21 . Eye examination revealed the presence of severe ophthalmopathy, disfiguring bilateral periorbital edema, marked proptosis of the right globe, diplopia due to profound extraocular muscle dysfunction, and right optic neuropathy. Computed tomography of the orbits suggested compression of the right optic nerve at the orbital apex by markedly enlarged extraocular muscles. Orbital decompression of the right orbit was performed and resulted in rapid improvement of optic nerve functions and periorbital swelling. A small biopsy specimen was obtained from the retroorbital connective tissue and stored in liquid nitrogen for further analysis. In addition, several biopsies were taken from an area of diffuse thickening and redness of the skin that extended from the pretibial area to the forefoot of her left leg. Histology was consistent with pretibial dermopathy. HLA haplotyping of patient 2 revealed HLA dlass I (A1, A2, B13, Cw6, Cw7), HLA class II (DR2, DR7).

In addition, biopsies of thyroid, retroorbital, and pretibial tissue were obtained from two females ( 48 and 61 yr of age, respectively) who died from fatal myocardial infarction. None of these individuals had a personal or family history of GD, GO, or systemic or organ-specific autoimmune disease. Thyroid function studies were normal, and thyroid autoantibodies were not detected.

\section{Sample preparations}

Biopsies, taken from thyroid gland, retroorbital tissue, and pretibial skin, were rapidly frozen in liquid nitrogen for subsequent RNA extraction. Peripheral blood lymphocytes (PBL) were prepared from heparinized blood by Ficoll-Hypaque density-gradient centrifugation (Pharmacia, Piscataway, NJ) and stored in liquid nitrogen. Immunohistochemical staining of $\mathrm{T}$ lymphocytes in frozen sections was performed using monoclonal antibodies directed against CD2, CD3, CD4, and CD8 (Becton Dickinson, Mountain View, CA); CD45RO (Dakopatts Corp., Santa Barbara, CA); $\alpha / \beta \mathrm{TcR}$ (Identi T $\beta \mathrm{F} 1, \beta$-chain specific) and TcR $\gamma / \delta$ (TcR 81 ; T Cell Science Co., Cambridge, MA); TcRV $\beta 2$ (Dianova, Hamburg, Germany); and TcRV $\beta 6$ (T Cell Diagnostics, Woburn, MA) and biotinylated secondary antibodies in conjunction with the Vectastain Peroxidase $A B C$ elite kit (Vector Laboratories, Burlingame, $C A$ ), as described previously $(9,24)$.

\section{PCR analysis of $T c R V$ genes}

TcR V gene analysis was performed as previously described $(24,25)$. In brief, total RNA was extracted from cryostat sections and PBL, reverse transcribed to complementary DNA (cDNA), and amplified using $22 \mathrm{~V} \alpha$ family-specific primers and $23 \mathrm{~V} \beta$ family-specific primers, each paired with a $3^{\prime}$-primer matched to a single constant region of the $\mathrm{V} \alpha$ gene $(\mathrm{C} \alpha)$ and $V \beta$ gene $(C \beta)$. T cell antigen receptor $V$ gene-specific primer sequences, oligonucleotide probe sequences, and the expected sizes of the PCR products were previously reported (24). To avoid technical artifacts, samples were prepared and analyzed together. Southern hybridization was performed to increase the sensitivity of fragment detection and to verify the specificity of PCR products, as previously reported (24). The proportions of TCR $V$ genes expressed were determined by computerized quantitative densitometry of autoradiographs. Each TcR $V \alpha$ or $\mathrm{V} \beta$ gene was expressed as a percentage of all of the $\mathrm{V} \alpha$ or $\mathrm{V} \beta$ genes 
detected on that scan, respectively. Control experiments were performed as previously described (24). Comparable quantities of TcR-specific CDNA, as indicated by the yield of TCR C region-specific transcripts, were subjected to PCR analysis. Hybridization conditions were of sufficient stringency to allow for specific detection of fragments of defined and predicted size (24).

\section{Cloning and sequencing of $c D N A$ s encoding $T c R V \beta$ genes}

Amplified cDNAs encoding particular TcR $V$ genes from $T$ cells infiltrating the thyroid gland or extrathyroidal were size-fractionated on $2 \%$ agarose gels and purified using the Qiaex agarose gel extraction procedure (Qiagen, Chatsworth, CA). Purified DNA fragments were ligated into PCR II T/A cloning vector (Invitrogen, San Diego, CA) and used to transform bacterial cells. Independent recombinants were identified by antibiotic selection and a $\beta$-galactosidase colorimetric assay. Individual bacterial colonies were grown overnight in minicultures and screened subsequently by DNA blot hybridization using a TCR $C \beta$ specific horseradish peroxidase probe. Plasmid DNA was purified from positively hybridizing bacterial lysates using Qiaex silica matrix and eluted in $30 \mu \mathrm{L} \mathrm{dH_{2 }} \mathrm{O}$. Half of the plasmid miniprep was subjected to double stranded DNA sequencing using T7 and SP6 primers, respectively, and the Sequenase V.2 protocol (U.S. Biochemical Corp., Cleveland, $\mathrm{OH}$ ). Nucleic acid and protein sequence comparisons were conducted using GenBank and EMBL libraries.

\section{Results \\ Immunoperoxidase detection of $T c R$ chains}

Immunohistochemistry of sections derived from thyroid, retroorbital, and pretibial tissue samples of both patients revealed the presence of $\mathrm{CD}^{+} \mathrm{T}$ cells. The vast majority of T lymphocytes ( $\sim 96-98 \%)$ were $\alpha / \beta^{+}$T cells, as determined by positive immunoreaclivity with a $\beta$-chain-specific human TcR antibody (data not shown). Except for occasional cells immunoreactive with the human TcR $\delta$-chain-specific monoclonal antibody, $\gamma \delta^{+} \mathrm{T}$ cells were not detected in thyroid, retroorbital, and pretibial specimens of either patient.

\section{$T$ cell antigen receptor $V$ gene analysis}

Expression of a broad spectrum of $T c R \mathrm{~V} \alpha$ and $\mathrm{V} \beta$ genes was detected in CDNA samples prepared from PBL of either patient (Fig. 1; 1:B and 2:B) and two control individuals (data not shown). In these samples, between $19-20 \mathrm{~V} \alpha$ genes and between $20-22 \mathrm{~V} \beta$ genes, respectively, were actively transcribed. Compared with PBL, restriction of TcR V $\alpha$ and TcR $V \beta$ genes $(<50 \%$ of individual genes rearranged and expressed) was detected in thyroid ( 7 of $22 \mathrm{~V} \alpha$ gene families; 10 of $23 \mathrm{~V} \beta$ gene families), retroorbital (9 of $22 \mathrm{~V} \alpha$ gene families; 10 of $23 \mathrm{~V} \beta$ gene families), and pretibial (8 of $22 \mathrm{~V} \alpha$ gene families; 9 of $23 \mathrm{~V} \beta$ gene families) tissue obtained from patient 1 (Fig. 1). Similarly, marked restriction of TcR $V \alpha$ and TCR V $\beta$ genes was detected in retroorbital $(8$ of $22 \mathrm{~V} \alpha$ gene families; 8 of $23 \mathrm{~V} \beta$ gene families) and pretibial ( 8 of $22 \mathrm{~V} \alpha$ gene families; 8 of $23 \mathrm{~V} \beta$ gene families) tissue obtained from patient 2 (Fig. 1). The presence of dominant TcR V $\beta 2$ and V $\beta 6$ gene products in thyroid, orbital, and pretibial tissue of patient 1 and in orbital and pretibial tissue of patient 2 was further confirmed by immunohistochemical staining using monoclonal antibodies directed against human TcR V $\beta 2$ and TcR V $\beta 6$ gene families, respectively (Fig. 2). Further, unrestricted TcR $V \alpha$ or $V \beta$ gene usage was detected in samples derived from the thyroid gland of two control individuals. TCR V gene analysis of retroorbital and pretibial specimens derived from these two control individuals failed to yield TcR-specific transcripts (not shown).

Despite obvious heterogeneity of the $T c R$ V gene repertoire between patients 1 and 2, marked similarities of restricted $V \boldsymbol{\alpha}$ and $V \beta$ gene family usage were noted in T cells infiltrating the thyroid gland, retroorbital connective tissue, and pretibial skin of either patient. For example, the presence of $\mathrm{V} \alpha 2, \mathrm{~V} \alpha 3, \mathrm{~V} \alpha 8, \mathrm{~V} \alpha 12, \mathrm{~V} \alpha 15, \mathrm{~V} \alpha 21, \mathrm{~V} \beta 2, \mathrm{~V} \beta 4, \mathrm{~V} \beta 6, \mathrm{~V} \beta 7$, $\mathrm{V} \beta 12, \mathrm{~V} \beta 20$, and $\mathrm{V} \beta 24$ transcripts, was shared by thyroid, retroorbital, and pretibial tissue of patient 1 . Further, $V \alpha 3$, $\mathrm{V} \alpha 8, \mathrm{~V} \alpha 12, \mathrm{~V} \alpha 14, \mathrm{~V} \alpha 19, \mathrm{~V} \beta 2, \mathrm{~V} \beta 4, \mathrm{~V} \beta 6, \mathrm{~V} \beta 12, \mathrm{~V} \beta 18$, and $\mathrm{V} \beta 23$ transcripts were present in both retroorbital and pretibial tissue obtained from patient 2 .

DNA sequencing was used to determine the amino acid sequences of dominant TcR V gene families that contributed $20 \%$ or more of the total $\mathrm{V} \beta$ gene activity detected at individual sites. TcRs using V $\beta 6$ (patient 1 ) and $V \beta 2$ (patient 2) genes, respectively, were amplified by PCR and ligated into pCR II T/A cloning vector. Multiple TcRs were then isolated from these libraries and sequenced. The results of this analysis are summarized in Table 1 . Overexpressed $V \beta 2$ and $V \beta 6$ gene families from thyroid, orbital, and pretibial tissues of patients 1 and 2, respectively, revealed major populations of clonally expanded TcRs or TcRs whose rearrangements shared significant homologies at the amino acid level of junctional regions. As demonstrated by sequence analysis of $51 \mathrm{~V} \beta 6$ TcR cDNA clones derived from the involved tissue sites (thyroid, orbit, and pretibium) of patient 1 and of $29 \mathrm{~V} \beta 2$ TcR cDNA clones from the orbit and pretibium of patient 2 , single TcR rearrangements accounted for up to $53 \%$ (intrathyroidal TcRs in patient 1 ) of a given TcR family. One TcR clone using V $\beta 6.2$ (V $\beta 6.2-\mathrm{J} \beta 2.1$ ) was detected in thyroidal, orbital, and pretibial tissue of patient 1 . In addition, a restricted number of $J \beta$ gene family members was detected in distinct tissue sites of either patient. Of the $13 \mathrm{~J} \beta$ gene family members, only $4(\mathrm{~J} \beta 1.6,-2.1,-2.2$, and -2.3$)$ were used by intrathyroidal, orbital, and pretibial TCR V $\beta 6$ clones in patient 1 , and $5(\mathrm{~J} \beta 1.5,-2.1,-2.2,-2.3$, and 2.7$)$ were preferentially used by orbital and pretibial TcR V $\beta 2$ clones in patient 2. Further, comparison of the CDR3 domains of junctional regions in expanded $V \beta T C R$ revealed several conserved amino acid motifs that were shared by intrathyroidal, orbital, and pretibial lymphocytes in either patient (Table 1). In V $\beta 6$ TcRs of patient 1 , the motif G-L-A was used by the dominant intrathyroidal clonotype, and by one of the clonally expanded V $\beta 6$ orbital and pretibial TcRs, respectively. Similarly, in patient 2, the motifs E-R-G and G-Q-E-L were shared by clonally expanded $V \beta 2$ orbital and pretibial TcRs, respectively. In contrast, none of the dominant rearrangements was found among V $\beta 2$ and V $\beta 6$ TcR cloned from PBL from either patient. These results indicate that certain populations of intrathyroidal, orbital, and pretibial lymphocytes in these 2 patients were oligoclonal, and that several clones were present at a high frequency in these distinct sites.

\section{Discussion}

$\mathrm{T}$ lymphocytes are thought to play a crucial role in the pathogenesis of GD, GO, and PTD $(1,2,10,24,25)$. Analysis of lymphocytes infiltrating the retroorbital and pretibial 
FIG. 1. TcR $V \alpha$ and $V \beta$ gene family usage in tissue samples derived from thyroid gland, orbital connective tissue, and pretibial skin of patient 1 (top panel) and patient 2 (bottom panel). RNA was extracted from frozen sections of tissue biopsies, transcribed to cDNA, and amplified by the PCR using $22 \mathrm{~V} \alpha$ and $23 \mathrm{~V} \beta$ primer pairs. The resulting transcripts were detected autoradiographically after Southern hybridization with digoxigenin-labeled $\operatorname{TcR} \alpha$ and $\beta$-chain-specific constant region oligonucleotide probes. The relative proportions of individual $\mathrm{TcR} V \alpha$ and $\mathrm{V} \beta$ genes detected were determined by quantitative densitometry and expressed as percentages (percent contribution) of the $22 \mathrm{~V} \alpha$ and $23 \mathrm{~V} \beta$ genes examined. Only TCR $\mathrm{V} \alpha$ and $\mathrm{V} \beta$ genes with a more than $1 \%$ overall contribution are depicted. In patient 1 , intrathyroidal ( $\mathrm{T})$, orbital $(\mathrm{O})$, and pretibial (P) $\mathrm{TcR} V \alpha$ and $V \beta$ gene usage is shown. In patient 2 , orbital $(O)$, and pretibial (P) TcR V $\alpha$ and $V \beta$ gene usage is demonstrated. In addition, nonrestriction of peripheral blood (B) $\mathrm{TcR} V \alpha$ and $\mathrm{V} \beta$ gene usage was present in both patients.
1:T
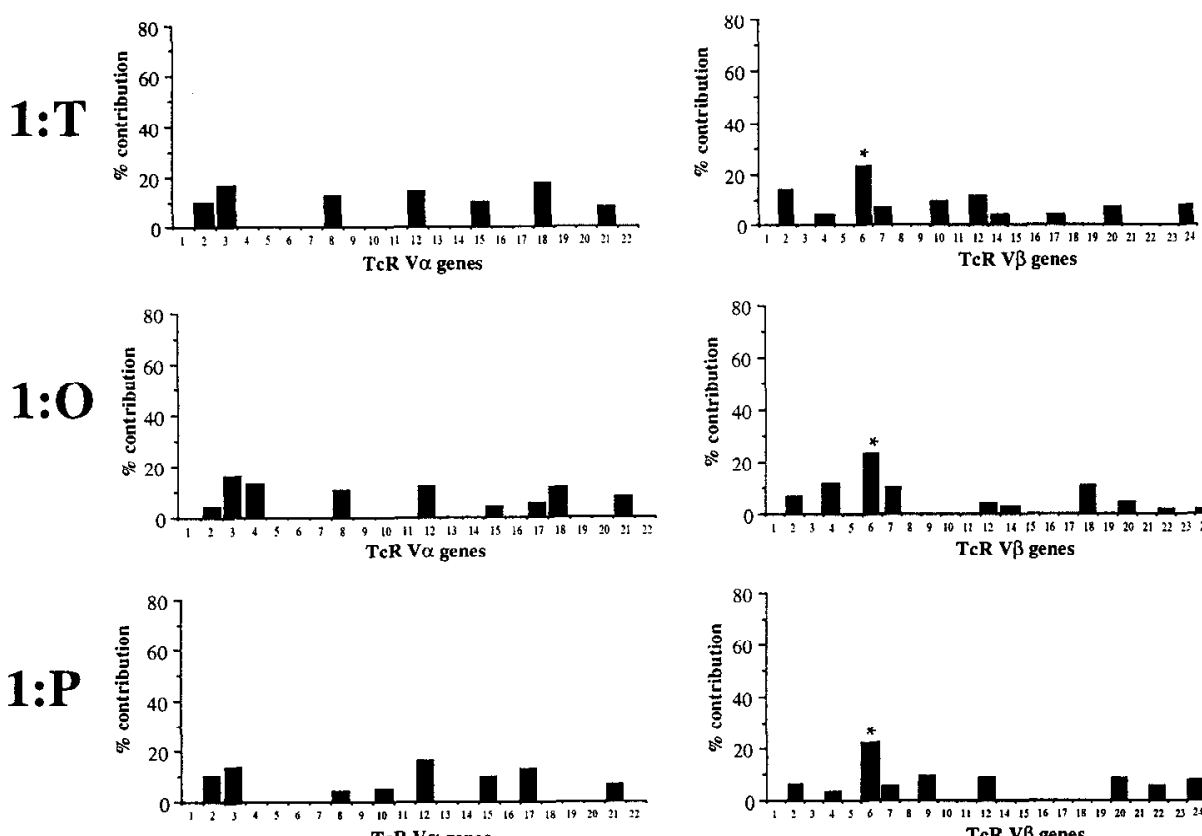

TcR V $\alpha$ genes
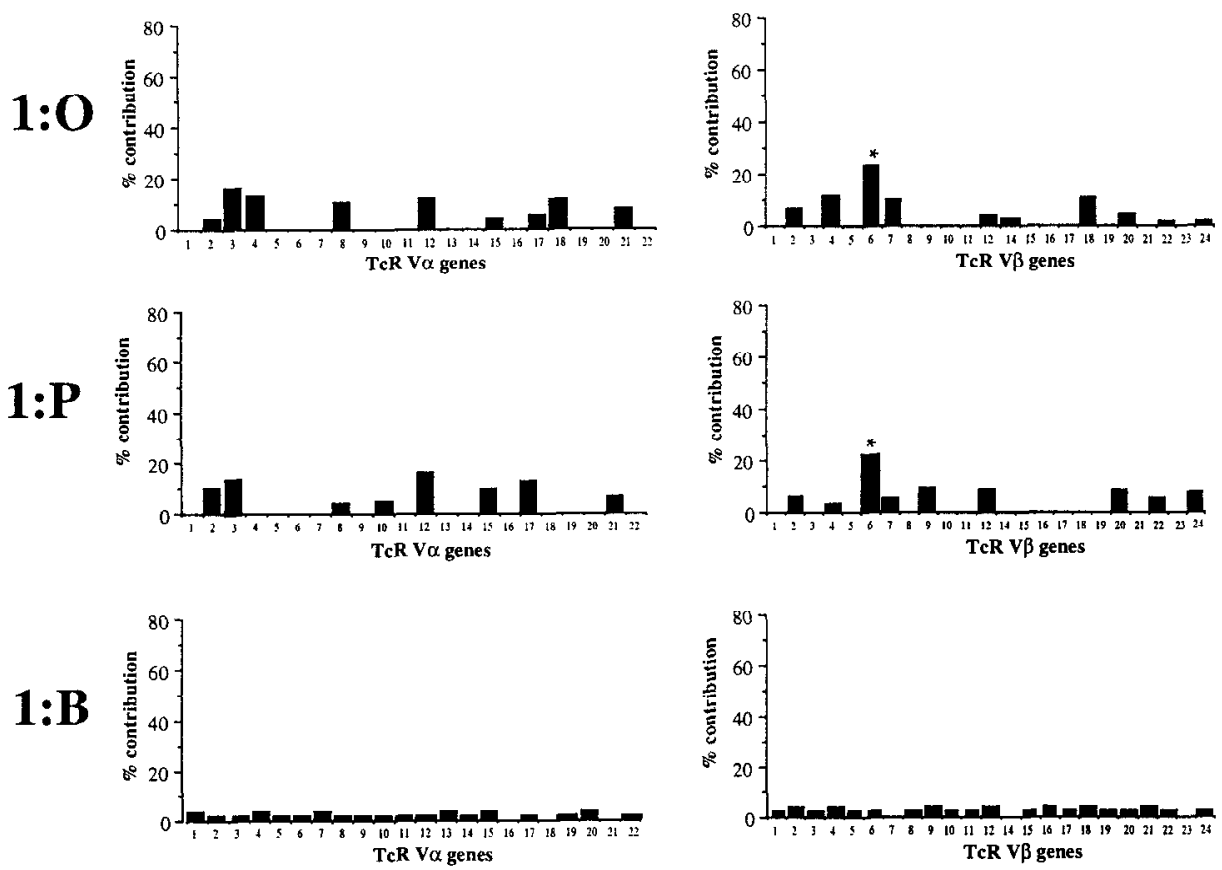

TcR V $\beta$ genes
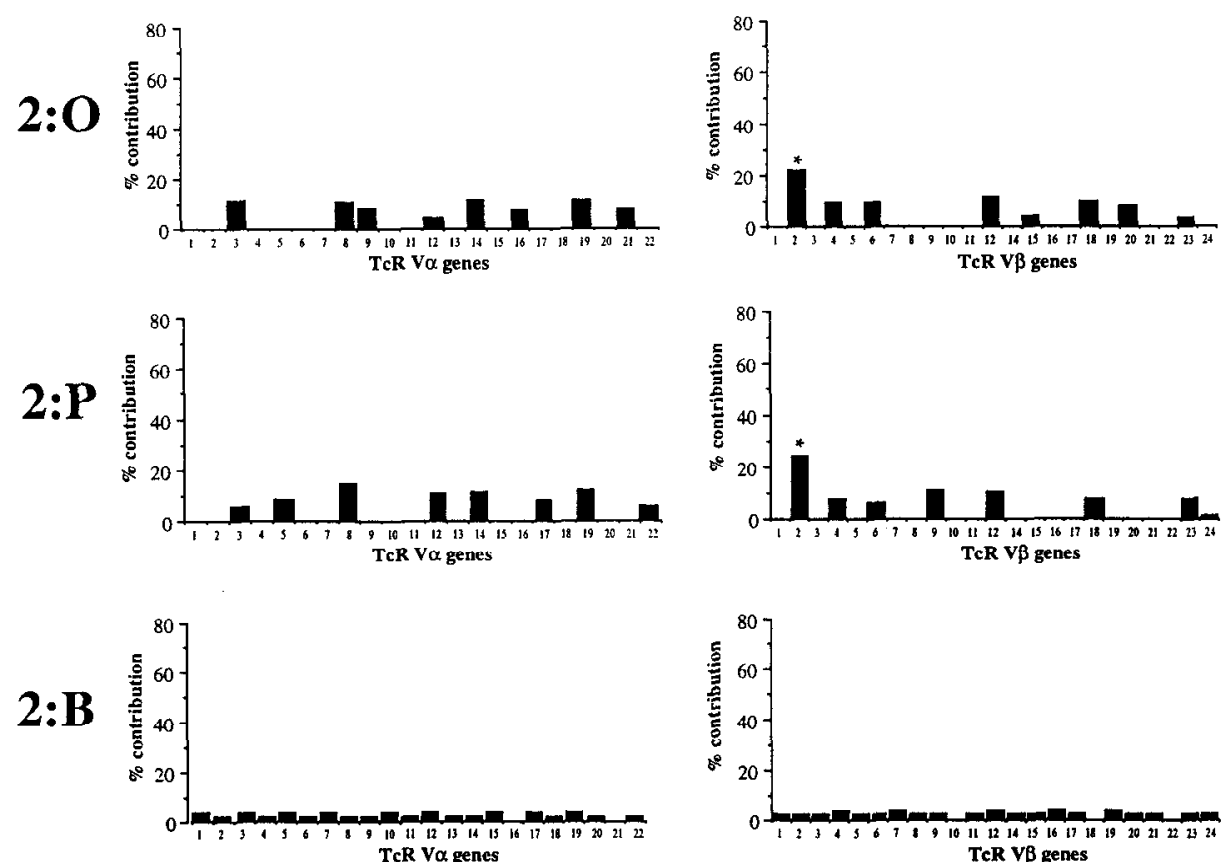

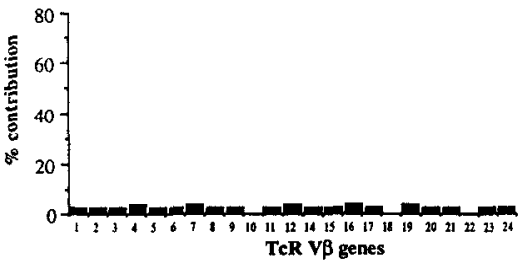

space of patients with GO and PTD revealed the presence of both $\mathrm{CD}^{+}$and $\mathrm{CD}^{+}$T lymphocytes, with a variable predominance of the latter $(1,2,6,7)$. A significant proportion of $\mathrm{T}$ lymphocytes, frequently adjacent to blood vessels, are
$\mathrm{CD}^{+} / \mathrm{CD} 45 \mathrm{RO}^{+}$cells, reflecting a subset of memory $\mathrm{T}$ cells and macrophages (8). However, the autoantigens recognized by autoreactive $T$ cells infiltrating the thyroidal and extrathyroidal manifestations of patients with GD have not been 


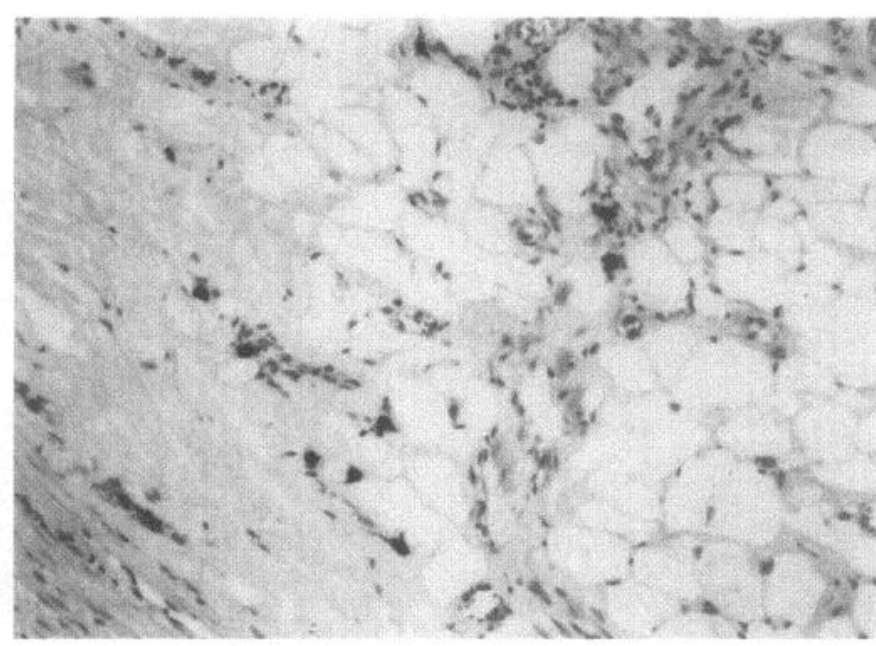

FIG. 2. Immunoperoxidase localization of $\mathrm{TcR} V \beta 6^{+}$lymphocytes in a cryostat section of retroorbital connective tissue derived from patient 1 with GD, severe ophthalmopathy, and pretibial dermopathy. Infiltration of retroorbital connective tissue by $\mathrm{TcR} \mathrm{V} \beta 6^{+}$lymphocytes (arrows) is demonstrated. Original magnification, $\times 250$.

identified (10). In a recent study, $\mathrm{CD}^{+} \mathrm{CD}^{+} 5 \mathrm{RO}^{+}$orbitinfiltrating $\mathrm{T}$ lymphocytes from patients with GO were demonstrated to selectively recognize autologous fibroblasts derived from retroocular connective tissue and, to a lesser degree, other anatomical locations (14). These results support the concept that connective tissue fibroblasts represent major targets for $\mathrm{T}$ cells that infiltrate the extrathyroidal manifestations associated with GD (26). Recent data from several laboratories have demonstrated TcR V gene restriction in both animal models and human autoimmune diseases, supporting a central role for $\mathrm{T}$ cells in the initiation and propagation of autoimmunity (17-20). In support of this concept, evidence of limited variability of intrathyroidal TcR V genes in GD has been demonstrated (21-23), although conflicting results have also been reported $(27,28)$. We have recently detected restriction of TcR V gene usage in retroorbital connective tissue of patients with active GO of recent onset, whereas TcR V gene usage was unrestricted in patients with long standing, inactive GO (24). In addition, analysis of T cell surface markers and TcRs expressed by lymphocytes infiltrating the pretibial space of patients with clinically active PTD revealed a predominance of $\mathrm{CD}^{+} \mathrm{T}$ lymphocytes, many of which are $\mathrm{CD} 8^{+} \mathrm{T}$ cells and express $\mathrm{TcR} \alpha / \beta$-chains (25). Marked restriction of TcR $V \alpha$ and $V \beta$ gene usage was demonstrated in lymphocytes infiltrating the pretibial tissue of patients with early active PTD, whereas greater diversity of $\mathrm{V} \beta$ gene usage and loss of $\mathrm{V} \alpha$ gene restriction were observed in patients with long standing pretibial dermopathy (25). These results suggested that the primary target antigen in GO and PTD may initiate a restricted T cell V gene response, and that later in the natural history of the disease, tissue destruction and cytokine-induced antigen expression may promote the recruitment of a more diverse spectrum of $\mathrm{T}$ cells that use multiple $\mathrm{TcR} \mathrm{V}$ gene families, and react to a variety of tissue-specific and tissue-nonspecific antigens (29).

We hypothesized that among the inflammatory cells infiltrating thyroid, retroorbital, and pretibial tissues of individual patients with GD, subpopulations of autoantigen- reactive $T$ cells may be responsible for initiating and perpetuating the immune process. To identify such diseaseassociated T cells, we have analyzed the patterns of TcR- $\alpha \beta$ gene expression and sequenced the junctional regions of dominating $\mathrm{TcR} V \beta$ genes in thyroid, retroorbital, and pretibial tissue samples derived from two patients with GD, GO and PTD. Although the spectrum of actively transcribed $\mathrm{TcR} V \alpha$ and $\mathrm{V} \beta$ genes varied among the various samples derived from either patient, several striking features were noted. Marked restriction of the TcR V gene repertoire and overexpression of certain $\mathrm{TcR} V$ gene segments were detected in lymphocytes infiltrating thyroid, orbital, and pretibial skin. Heterogeneity of TcR V gene usage may be explained by the fact that the TcR recognizes similar antigenic peptides in the context of HLA molecules, which were different in the two patients studied. Individual HLA gene endowment may play an important role in shaping the TcR $V$ gene repertoire $(30,31)$, and this may influence TcR $V$ gene usage in lymphocytes capable of recognizing common antigenic epitopes presented at distinct involved sites in GD. Given the marked similarity in individual TcR V genes expressed by lymphocytes infiltrating distinct anatomical sites, our results suggest that infiltrating $\mathrm{T}$ cells might recognize a limited range of antigenic epitopes shared by the thyroid gland, retroorbital connective tissue, and pretibial skin. Furthermore, our data indicate that analogous mechanisms may act to control $\mathrm{T}$ cell selection and expansion within both the thyroid gland and the involved extrathyroidal compartments.

To define further the significance of dominating $\mathrm{V} \beta 2$ and $\mathrm{V} \beta 6$ gene families in thyroid, retroorbital, and pretibial tissue of patients 1 and 2, we next examined the clonotypic heterogeneity of these T cells. Sequence analysis of the junctional regions of $V \beta 6$ and $V \beta 2$ genes revealed a limited number of independently rearranged $\mathrm{TcR} \beta$-chain genes, the presence of conserved amino acid residues within the CDR3 region, and selective usage of related $\mathrm{J} \beta$ gene family members by $\mathrm{V} \beta 6^{+}$ and $\mathrm{V} \beta 2^{+} \mathrm{T}$ cells infiltrating distinct tissues in the two patients studied. By contrast, limited clonotypic heterogeneity and biased $\mathrm{J} \beta$ gene usage were not detected among patients' PBL or in tissue controls obtained from healthy individuals. The CDR3 region is commonly associated with fine antigenic specificity, and TcRs selected by defined antigenic peptides often show homologous amino acid motifs in the junctional region (16). Accordingly, detection of conserved CDR3 motifs in clonally expanded TcR from distinct anatomical sites is consistent with $\mathrm{T}$ cell activation by antigens bearing shared antigenic determinants. Given the similarity of certain HLA alleles in the two patients studied, detection of conserved junctional motifs may reflect the influence of common HLA alleles on TcR selection. The presence of conserved junctional CDR3 motifs joined to different $V \beta$ segments has been reported in several HLA class I-restricted T cell lines and T cell clones specific for the same peptide/MHC complex or in tissues affected by autoimmune conditions, such as giant cell arteritis $(32,33)$. Thus, homologous junctional regions appear to confer specificity for the same antigenic determinant even if associated with different $\mathrm{V} \beta$ segments. Our detection of a limited number of independently rearranged TcR $\beta$-chain genes together with selective usage of related TcR J $\beta$ gene 
Table 1. Summary of junctional sequence analysis of $T c R$ V $\beta$ genes in $T$ lymphocytes rescued from thyroid, orbital, pretibial tissue, and peripheral blood of two patients with Graves' disease, ophthalmopathy, and pretibial myxedema

\begin{tabular}{|c|c|c|c|c|c|c|c|}
\hline \multirow{2}{*}{ Patient no. } & \multirow{2}{*}{ Source } & \multirow{2}{*}{$\mathrm{TcR} V \beta$} & \multirow{2}{*}{ No. of clones } & \multirow{2}{*}{$\%$ of total } & \multicolumn{3}{|c|}{$T c R \beta-V-N(n) N-J$ junctional sequences } \\
\hline & & & & & $\mathrm{V} \beta$ & $\mathrm{N}-\mathrm{D} \beta-\mathrm{N}$ region $^{\alpha}$ & $\mathrm{J} \beta$ \\
\hline \multirow[t]{9}{*}{1.} & Thyroid & $\mathrm{V} \beta 6$ & $8 / 15$ & 53.3 & VB6.2-CASS & RGLA & 2.1 \\
\hline & & & $3 / 15$ & 20.0 & V $\beta 6.2$ CASSL & GTAS & 2.2 \\
\hline & & & $1 / 15$ & 6.7 & V $\beta 6.2$ CASS & YSGIT & 2.1 \\
\hline & Orbit & $\mathrm{V} \beta 6$ & $5 / 17$ & 29.4 & VB6.1 CASSL & GQG & 2.1 \\
\hline & & & $2 / 17$ & 11.8 & V $\beta 6.2$ CASS & DGLA & 2.3 \\
\hline & Pretibium & $\mathrm{V} \beta 6$ & $7 / 19$ & 36.8 & V $\beta 6.2$ CASSL & PGGGR & 2.1 \\
\hline & & & $2 / 19$ & 10.5 & V $\beta 6.2$ CASS & LAGGLG & 2.3 \\
\hline & & & $2 / 19$ & 10.5 & V $\beta 6.2$ CASSL & DGLA & 1.6 \\
\hline & Blood & $\mathrm{V} \beta 6$ & $0 / 19$ & 0 & & & \\
\hline \multirow[t]{7}{*}{2} & Orbit & $\mathrm{V} \beta 2$ & $6 / 16$ & 37.5 & $\mathrm{~V} \beta 2.1 \mathrm{CSA}$ & TGQELG & 1.5 \\
\hline & & & $5 / 16$ & 31.3 & V $\beta 2.3$ CSAR & GERGS & 2.3 \\
\hline & & & $2 / 16$ & 12.5 & V $\beta 2.3$ CSAR & DPERGA & 2.7 \\
\hline & Pretibium & $\mathrm{V} \beta 2$ & $4 / 13$ & 30.8 & $V \beta 2.1 \mathrm{CSA}$ & $\mathrm{RTAY}$ & 2.1 \\
\hline & & & $2 / 13$ & 15.4 & V $\beta 2.1 \mathrm{CSA}$ & NGQELV & 2.1 \\
\hline & & & $1 / 13$ & 7.7 & $\mathrm{~V} \beta 2.1 \mathrm{CSA}$ & $\mathrm{RDN}$ & 2.2 \\
\hline & Blood & $\mathrm{V} \beta 2$ & $0 / 19$ & 0 & & & \\
\hline
\end{tabular}

\footnotetext{
${ }^{a}$ The single letter amino acid sequences at the $3^{\prime}$-position of $\mathrm{TcR} V \beta$ and at the CDR3 region are given. Repetitive amino acid motifs within
} the junctional regions are underlined.

family members by V $\beta 2$ and $V \beta 6 \mathrm{~T}$ cells infiltrating thyroid, retroorbital, and pretibial tissues suggest clonal restriction of these cells, perhaps in response to local stimulation by one or a limited number of antigenic determinants present in these distinct anatomical locations. Although the significance of this apparent bias remains unclear, it is interesting to speculate that the V $\beta 6.2-J \beta 2.1$ clonotype may define a distinct antigenic reactivity, perhaps unique to patient 1 . It is likely that V $\beta 2$ - and V $\beta 6$-positive $T$ cells proliferate due to antigen-driven stimulation through MHC-antigen-TCR complexes, although the possibility that these cells proliferate in response to a superantigen must be considered.

Involvement of $\mathrm{V} \beta 2^{+}$and $\mathrm{V} \beta 6^{+} \mathrm{T}$ lymphocytes has been observed in several other immune responses affecting gut $(34,35)$, muscle $(36)$, and skin $(37,38)$. Clonally expanded $\mathrm{V} \beta 6^{+} \mathrm{T}$ cells appear to confer protective immunity to $\mathrm{My}$ cobacterium leprae (39), and $\mathrm{V} \beta 2^{+}$and $\mathrm{V} \beta 6^{+} \mathrm{T}$ lymphocytes have been attributed antitumor activity against squamous cell carcinomas (40). In addition, $\mathrm{V} \beta 2$ and $\mathrm{V} \beta 6 \mathrm{~T} \mathrm{~T} R \mathrm{~s}$ are highly expressed in the intestinal mucosa (35). In GD and its associated extrathyroidal manifestations, recent evidence suggests that the immune response may be directed against certain antigenic determinants that are present in epithelial (thyroid, skin, and orbit) and mucosal (lacrimal gland) tissue components $(41,42)$. Thus, in view of our previous and current data, and the proposed functions of V $\beta 2$ and V $\beta 6$ TcRs in conveying immunosurveillance over mucosal and epithelial surfaces, the role of $V \beta 2$ and $V \beta 6$ TcRs in GD warrants further study.

Although the antigens to which $T$ cells infiltrating thyroid, retroorbital, and pretibial tissue in patients with GD respond are unknown, delineation of antigenic reactivities associated with tissue-infiltrating $\mathrm{T}$ lymphocytes of patients with GD may help to clarify the significance of the TcR restrictions identified in this study. Analysis of ligands, including selfantigens and HLA alleles, that are recognized by restricted autoreactive $\mathrm{T}$ cells should shed light on the mechanisms involved in the evolution of the extrathyroidal manifesta- tions of GD. Thus, if the recurrent character of TcR rearrangements in $T$ cells infiltrating the involved tissues could be confirmed in a larger number of patients with GD who share certain HLA alleles, this approach might ultimately provide a basis for targeted immunotherapy in patients with thyroidal and extrathyroidal manifestations of GD.

In conclusion, we have demonstrated restriction of TcR $V \alpha$ and $V \beta$ gene usage and overexpression of certain dominating $\mathrm{TcR} V \boldsymbol{\alpha}$ and $\mathrm{V} \boldsymbol{\beta}$ gene families in thyroid, retroorbital, and pretibial tissue of two patients with GD. Furthermore, detection of TcR oligoclonality and marked homology of TcR $\mathrm{V}$ genes rearranged and expressed by $\mathrm{T}$ cells infiltrating into these anatomically distinct tissues indicate that similar mechanisms may act to locally control $\mathrm{T}$ cell recruitment and expansion within thyroid, orbital, and pretibial tissues in GD. These similarities may be considered molecular evidence that some of the clonally expanded intrathyroidal $\mathrm{T}$ cells were strongly selected. Thus, our data are consistent with the hypothesis that in GD, common antigenic determinants may drive the immune response against the thyroid gland and certain extrathyroidal sites. Although the nature of the antigen and the mechanisms leading to its recognition by the immune system await further study, the expression of certain antigenic epitopes by a cell type common to the thyroid gland and the affected extrathyroidal tissues remains a strong possibility.

\section{References}

1. Burch HB, Wartofsky L. 1993 Graves' ophthalmopathy: current concept regarding pathogenesis and management. Endocr Rev. 14:747-793.

2. Bahn RS, Heufelder AE. 1993 Mechanisms of disease: pathogenesis of Graves' ophthalmology. N Engl J Med. 329:1468-1475.

3. Kriss JP. 1987 Pathogenesis and treatment of pretibial myxedema. Endocrinol Metab Clin North Am. 16:409-415.

4. Elte JW, Hensen EJ. 1983 Pretibial myxoedema: report of $\mathbf{1 7}$ cases and review of the literature. Neth J Med. 26:220-227.

5. Fatourechi V, Pajouhi M, Fransway AF. 1994 Dermopathy of Graves' disease (pretibial myxedema). Medicine. 73:1-7.

6. Weetman AP, Cohen S, Gatter KC, Fells D, Shine B. 1989 Immunohistochemical analysis of the retrobulbar tissues in Graves' ophthalmopathy. Clin Exp Immunol. 75:222-227. 
7. de Carli M, D'Elios M, Mariotti S, et al. 1993 Cytolytic T cells with Th-1-like cytokine profile predominate in retroorbital lymphocytic infiltrates of Graves ophthalmopathy. J Clin Endocrinol Metab. 77:1120-1124.

8. Heufelder AE, Bahn RS. 1993 Elevated expression in situ of selectin and immunoglobulin superfamily adhesion molecules in retroocular connective tissues from patients with Graves' ophthalmopathy. Clin Exp Immunol. 91:381-389.

9. Heufelder AE, Bahn RS. 1993 Detection and localization of cytokine immunoreactivity in retroocular connective tissue in Graves' ophthalmopathy. Eur $\mathrm{J}$ Clin Invest. 23:10-17.

10. Konrad K, Brenner W, Pehamberger H. 1980 Ultrastructural and immunological findings in Graves' disease with pretibial myxedema. J Cutaneous Pathol. 7:99-108.

11. Heufelder AE. 1995 Pathogenesis of Graves' ophthalmopathy: recent contro versies and progress. Eur J Endocrinol. 132:532-541.

12. Smith TJ, Bahn RS, Gorman CA. 1989 Connective tissue, glycosaminoglycans, and diseases of the thyroid. Endocr Rev 10:366-391

13. Gorman CA, Heufelder AE, Bartley GBB. 1995 Ophthalmopathy. In: DeGroot L, ed. Endocrinology, 3rd ed. Philadelphia: Saunders; vol 1-3:712-725.

14. Grubeck-Loebenstein B, Trieb K, Sztankay A, Holter W, Anderl H, Wick G 1994 Retrobulbar T cells from patients with Graves' ophthalmoapthy are CD8 ${ }^{+}$ and specifically recognize autologous fibroblasts. J Clin Invest. 93:2738-2743.

15. Jorgensen JL, Reay PA, Ehrich EW, Davis MM. 1992 Molecular components of T-cell recognition. Annu Rev Immunol. 10:835-873.

16. Davis MM, Chien Y. 1993 Topology and affinity of T-cell receptor mediated recognition of peptide-MHC complexes. Curr Opin Immunol. 5:45-49.

17. Williams WV, Fang Q, Demarco D, Von FeIdt J, Zurier RB, Weiner DB. 1992 Restricted heterogeneity of $\mathrm{T}$ cell receptor transcripts in rheumatoid synovium. J Clin Invest. 90:326-333.

18. Blumberg RS, Yockey CE, Gross GG, Ebert E, Balk SP. 1993 Human intestina intraepithelial lymphocytes are derived from a limited number of $\mathrm{T}$ cell clones that utilize multiple V $\beta$ T cell receptor genes. J Immunol. 150:5144-5153.

19. Oksenberg JR, Stuart S, Begovich AB, et al. 1990 Limited heterogeneity of rearranged $T$-cell receptor $V$ alpha transcripts in brains of multiple sclerosis patients. Nature. 345:344-346

20. Bucht A, Oksenberg JR, Lindblad S, Grönberg A, Steinman L, Klareskog L. 1992 Characterization of T-cell receptor $\alpha \beta$ repertoire in synovial tissue from different temporal phases of rheumatoid arthritis. Scand J Immunol 35:159-165.

21. Davies TF, Martin A, Concepcion ES, Graves P, Cohen L, Ben-Nun A. 1991 Evidence of limited variability of antigen receptors on intrathyroidal $\mathrm{T}$ cells in autoimmune thyroid disease. N Engl I Med. 325:238-244.

22. Davies TF, Concepcion ES, Graves P, Lahat N, Cohen WL, Ben-Nun A. 1992 Evidence for selective accumulation of intrathyroidal $\mathrm{T}$ lymphocytes in human autoimmune thyroid disease based on $\mathrm{T}$ cell receptor $\mathrm{V}$ gene usage. $\mathrm{J}$ Clin Invest. 89:157-162.

23. Davies TF, Concepcion ES, Ben-Nun A, Graves PN, Tarjan G. 1993 T-cell receptor $\mathrm{V}$ gene usage in autoimmune thyroid disease: direct assessment by thyroid aspiration. J Clin Endocrinol Metab. 76:660-666.

24. Heufelder AE, Herterich S, Ernst G, Bahn RS, Scriba PC. 1995 Analysis of retroorbital $\mathrm{T}$ cell antigen receptor variable region gene usage in patients with Graves'. ophthalmopathy. Eur J Endocrinol. 132:266-277.
25. Heufelder AE, Bahn RS, Scriba PC. 1995 Analysis of T-cell antigen receptor variable region gene usage in patients with thyroid-related pretibial dermopathy. J Invest Dermatol. 105:372-378.

26. Heufelder AE. 1995 Involvement of the orbital fibroblast and TSH receptor in the pathogenesis of Graves' ophthalmopathy. Thyroid. 5:331-340.

27. McIntosh RS, Watson PF, Pickerill AP, Davies R, Weetman AP. 1993 No restriction of intrathyroidal T cell receptor $\mathrm{V} \alpha$ families in the thyroid of Graves' disease. Clin Exp Immunol. 91:147-152.

28. McIntosh RS, Tandon N, Pickerill AP, Davies R, Barnett D, Weetman AP. 1993 IL-2 receptor-positive intrathyroidal lymphocytes in Graves' disease: analysis of $\mathrm{V} \alpha$ gene microheterogeneity. J Immunol. 151:3884-3893.

29. Lehmann PV, Forsthuber T, Miller A, Sercarz EE. 1992 Spreading of T- cell autoimmunity to cryptic determinants of an autoantigen. Nature. 358:155-158.

30. Pullen AM, Marrack AM, Kappler JW. 1988 The T-cell repertoire is heavily influenced by tolerance to polymorphic self-antigens. Nature. 335:796-801.

31. Gulwani-Akolkar B, Posnett DN, Janson CH, et al. 1991 T cell receptor V gene segment frequencies in peripheral blood $T$ cells correlate with human leucocyte antigen type. J Exp Med. 174:1139-1146.

32. Steinle A, Reinhardt C, Jantzer P, Schendel DJ. 1995 In vivo expansion of IILA-B35 alloreactive T cells sharing homologous T cell receptors: evidence for maintenance of oligoclonally dominated allospecificity by persistent stimulation with autologous MHC/peptide complex. J Exp Med. 181:503-513.

33. Weyand CM, Schönberger J, Oppitz U, Hunder NH, Hicok KC, Goronzy JJ. 1994 Distinct vascular lesions in giant cell arteritis share identical clonotypes. J Exp Med. 179:951-960.

34. Gross G, Schwartz VL, Stevens C, Ebert E, Blumberg RS, Balk SP. 1994 Distribution of dominant $T$ cell receptor $\beta$ chains in human intestinal mucosa. J Exp Med. 180:1337-1344.

35. Van Kerckhove $C_{r}$ Russel GJ, Deusch K, et al. 1992 Oligoclonality of human intestinal intraepithelial T cells. J Exp Med. 175:57-63.

36. O'Hanlon TP, Dalakas MC, Plotz PH, Miller FW. 1994 Predominant TCR- $\alpha \beta$ variable and joining gene expression by muscle-infiltrating lymphocytes in the idiopathic inflammatory myopathies. J Immunol. 152:2569-2576.

37. Murata H, Kita Y, Sakamoto A, et al. 1995 Limited TCR repertoire of infiltrating $\mathrm{T}$ cells in the kidneys of Sjögren's syndrome patients with interstitial nephritis. J Immunol. 155:4084-4089.

38. Lewis HM, Baker BS, Bokth S, et al. 1993 Restricted T cell receptor-V $\beta$ gene usage in the skin of patients with guttate and chronic plaque psoriasis. $\mathrm{Br} \mathrm{J}$ Dermatol. 129:514-520.

39. Wang X, Golkar L, Uyemura K, et al. $1995 \mathrm{~T}$ cells bearing V $\beta 6 \mathrm{~T}$ cell receptors in cell-mediated immune response to Mycobacterium leprae. I Immunol. 151:7105-7116.

40. Yasumura S, Weidmann E, Hirabayashi $H$, Johnson JT, Herberman RB, Whiteside TL. 1994 HLA restriction and T cell receptor $V \beta$ gene expression of cytotoxic T lymphocytes reactive with human squamous-cell carcinoma of the head and neck. Int J Cancer. 57:297-305.

41. Amold K, Metcalfe R, Weetman AP. 1995 Immunoglobulin A class fibroblast antibodies in patients with Graves' disease and pretibial myxedema. J Clin Endocrinol Metab. 80:3430-3437.

42. Wall J. 1995 Extrathyroidal manifestations of Graves' disease. J Clin Endocrinol Metab. 80:3427-3429. 